\title{
Evolution of the early Antarctic ice ages
}

3 Diederik Liebrand ${ }^{\mathrm{a}, 1}$, Anouk T. M. de Bakker ${ }^{\mathrm{b}, \mathrm{c}}$, Helen M. Beddow ${ }^{\mathrm{d}}$, Paul A. Wilson ${ }^{\mathrm{a}}$,

4 Steven M. Bohaty ${ }^{\mathrm{a}}$, Gerben Ruessink ${ }^{\mathrm{b}}$, Heiko Pälike ${ }^{\mathrm{e}}$, Sietske J. Batenburg ${ }^{\mathrm{f}, \mathrm{g}}$, Frederik J.

5 Hilgen $^{\mathrm{d}}$, David A. Hodell ${ }^{\mathrm{h}}$, Claire E. Huck ${ }^{\mathrm{a}}$, Dick Kroon ${ }^{\mathrm{i}}$, Isabella Raffi ${ }^{\mathrm{j}}$, Mischa J. M.

$6 \quad$ Saes $^{\mathrm{d}}$, Arnold E. van Dijk $^{\mathrm{d}}$, Lucas J. Lourens ${ }^{\mathrm{d}}$

7

$8{ }^{a}$ National Oceanography Centre Southampton, University of Southampton, Southampton,

$9 \quad \mathrm{UK}$

$10{ }^{\mathrm{b}}$ Department of Physical Geography, Faculty of Geosciences, Utrecht University, Utrecht,

11 The Netherlands

12 cLittoral Environnement et Sociétés (LIENSs), Université de La Rochelle, La Rochelle,

13 France

$14{ }^{\mathrm{d}}$ Department of Earth Sciences, Faculty of Geosciences, Utrecht University, Utrecht, The

15 Netherlands

$16{ }^{\mathrm{e}}$ MARUM-Center for Marine Environmental Sciences, University of Bremen, Bremen,

17 Germany

18 Institute of Geosciences, Goethe-University Frankfurt am Main, Frankfurt, Germany

19 gDepartment of Earth Sciences, University of Oxford, Oxford, UK

$20{ }^{\mathrm{h}}$ Department of Earth Sciences, University of Cambridge, Cambridge, UK

21 ischool of GeoSciences, Grant Institute, University of Edinburgh, Edinburgh, UK

22 jDipartimento di Ingegneria e Geologia (InGeo), Università degli Studi “G. d'Annunzio”

23 di Chieti-Pescara, Chieti Scalo, Italy 


\section{Abstract}

26 Understanding the stability of the early Antarctic ice cap in the geological past is of

27 societal interest because present-day atmospheric $\mathrm{CO}_{2}$ concentrations have reached

28 values comparable to those estimated for the Oligocene and the early Miocene epochs.

29 Here we analyze a new high-resolution deep-sea oxygen isotope $\left(\delta^{18} \mathrm{O}\right)$ record from the

30 South Atlantic Ocean spanning an interval between 30.1 and 17.1 Myr ago. The record

31 displays major oscillations in deep-sea temperature and Antarctic ice volume in response

32 to the $\sim 110$-kyr eccentricity-modulation of precession. Conservative minimum ice

33 volume estimates show that waxing and waning of at least $\sim 85$ to $110 \%$ the volume of the

34 present East Antarctic Ice Sheet is required to explain many of the $\sim 110$-kyr cycles.

35 Antarctic ice sheets were typically largest during repeated glacial cycles of the 'mid'

36 Oligocene ( $\sim 28.0$ to $\sim 26.3 \mathrm{Myr}$ ago $)$ and across the Oligocene-Miocene Transition ( $\sim 23.0$

37 Myr ago). Yet, the high-amplitude glacial-interglacial cycles of the mid Oligocene are

38 highly symmetrical, indicating a more direct response to eccentricity-modulation of

39 precession than their early Miocene counterparts, which are distinctly asymmetrical -

40 indicative of prolonged ice build up and delayed, but rapid, glacial terminations. We

41 hypothesize that the long-term transition to a warmer climate state with sawtoothed

42 shaped glacial cycles in the early Miocene was brought about by subsidence and glacial

43 erosion in West Antarctica during the late Oligocene and/or a change in the variability of

44 atmospheric $\mathrm{CO}_{2}$ levels on astronomical time scales that is not yet captured in existing

45 proxy reconstructions. 


\section{Keywords}

48 unipolar icehouse, early Antarctic ice sheet, Oligocene-Miocene, glacial-interglacial

49 cycle geometries, bispectral analysis

\section{Significance}

52 The Antarctic ice cap waxed and waned on astronomical time scales throughout the

53 Oligo-Miocene time interval. We quantify geometries of Antarctic ice age cycles, as

54 expressed in a new climate record from the South Atlantic Ocean, to track changing

55 dynamics of the unipolar icehouse climate state. We document numerous $\sim 110$-thousand

56 year long oscillations between a near-fully glaciated and deglaciated Antarctica that

57 transitioned from being symmetric in the Oligocene to asymmetric in the Miocene. We

58 infer that distinctly asymmetric ice age cycles are not unique to the late Pleistocene or to

59 extremely large continental ice sheets. The patterns of long-term change in Antarctic

60 climate interpreted from this record are not readily reconciled with existing $\mathrm{CO}_{2}$ records.

62 Author contributions: D.L., H.M.B., M.J.M.S., and A.E.D. generated the data. D.L. and

63 A.T.M.B. performed the statistical analyses. D.L., A.T.M.B., P.A.W., and S.M.B. wrote

64 the manuscript. All authors designed the study, discussed the results and commented on

65 the manuscript.

66

$67{ }^{1}$ To whom correspondence should be addressed. Email:

68 diederik.liebrand@noc.soton.ac.uk

69 
$\backslash$ body

\section{Introduction}

72 The early icehouse world of the Oligocene and early Miocene epochs (hereafter referred

73 to as Oligo-Miocene) is bracketed by two major climate events: the Eocene-Oligocene

74 Climate Transition ( $\sim 34$ Myr ago, EOT) and the onset of the Middle Miocene Climatic

75 Optimum ( $\sim 17$ Myr ago) (1). Deep-sea proxy records and sedimentological evidence

76 from the Antarctic continental shelves indicate the expansion of continental-size ice

77 sheets on Antarctica at the EOT $(2,3)$, and sedimentary records from the western Ross

78 Sea on the East Antarctic margin document large subsequent oscillations in ice-sheet

79 extent on astronomical time scales during the Oligo-Miocene (4). In contrast, large ice

80 sheets did not develop in the high northern latitudes until the late Pliocene (5). Thus, the

81 Oligo-Miocene presents an opportunity to study the dynamics of a unipolar (Antarctic)

82 icehouse climate state without the overprint of Northern Hemisphere ice sheets on

83 benthic foraminiferal $\delta^{18} \mathrm{O}$ records. Published proxy records of atmospheric $\mathrm{CO}_{2}$

84 concentration show a decline from the Oligocene to the Miocene $(6,7)$ that is broadly

85 contemporaneous with a strong minimum in the $\sim 2.4 \mathrm{Myr}$ eccentricity cycle at $\sim 24 \mathrm{Myr}$

86 ago (8), which would promote continental ice sheet expansion if radiative forcing was the

87 dominant control on ice volume. Previous studies using drill-core records from the deep

88 ocean demonstrate a climatic response to astronomical forcing for the Oligocene $(9,10)$

89 and parts of the Miocene (11-13). Yet to improve understanding of the behavior of the

90 climate/cryosphere system we need longer high-resolution records from strategic

91 locations that capture the changing response of the high latitudes to the combined effects

92 of $\mathrm{CO}_{2}$, astronomical forcing and tectonic boundary conditions. 


\section{Walvis Ridge Ocean Drilling Program Site 1264}

95 To shed new light on southern high-latitude climate variability through the Oligo-

96 Miocene, we analyze a new high-resolution benthic foraminiferal $\delta^{18} \mathrm{O}$ record from

97 Walvis Ridge, located in the southeastern Atlantic Ocean (Ocean Drilling Program Site

$981264 ; 2505 \mathrm{~m}$ water depth; 2000-2200 m paleo-water depth; $28.53^{\circ} \mathrm{S}, 2.85^{\circ} \mathrm{E}$, Fig. 1 ; (14,

99 15)). An astrochronology for Site 1264 was developed by tuning $\mathrm{CaCO}_{3}$ estimates to the

100 stable eccentricity solution independently of the benthic $\delta^{18} \mathrm{O}$ record (15). On the

101 eccentricity-tuned age model, the Site 1264 record spans a 13-Myr time window between

$102 \quad 30.1$ and 17.1 Myr ago and ranges between 405-kyr Eccentricity Cycles 74-43 and 2.4-

103 Myr Eccentricity Cycles 13-8 (Fig. 1; (15)), representing the first continuous record from

104 a single site spanning the 'mid' Oligocene to early Miocene. Five distinct time intervals

105 with clear multi-Myr climatic trends are identified in this new $\delta^{18} \mathrm{O}$ dataset from Walvis

106 Ridge: (i) an early Oligocene time interval of climate deterioration ( 30.1-28.0 Myr

107 ago); (ii) a generally cold but highly unstable mid-Oligocene time interval ( 28.0-26.3

108 Myr ago), which we refer to as the Mid Oligocene Glacial Interval (MOGI); (iii) a late

109 Oligocene time interval characterized by low-amplitude climate variability and stepwise

110 climatic amelioration ( $26.3-23.7 \mathrm{Myr}$ ago), confirming that this warming trend is a real

111 feature of Cenozoic climate history (9) rather than an artifact of composite records from

112 multiple sites in different ocean basins; (iv) a time interval of persistently high-amplitude

113 climate variability spanning the Oligocene-Miocene Transition (OMT) and the earliest

114 Miocene ( 23.7-20.4 Myr ago); and (v) a time interval of moderate-amplitude climate

115 variability during the latter part of the early Miocene ( 20.4-17.1 Myr ago). 
117 Following the MOGI, the late Oligocene warming phase proceeded in a series of three

118 distinct steps ( 26.3, 25.5, and $\sim 24.2 \mathrm{Myr}$ ago), with the peak warming/lowest ice

119 volume confined to a $\sim 500 \mathrm{kyr}$ period ( $24.2-23.7 \mathrm{Myr}$ ago). This climate state was

120 terminated by the OMT ( $23.7-22.7 \mathrm{Myr}$ ago), which consists of two rapid $\sim 0.5 \%$ o

121 increases in benthic $\delta^{18} \mathrm{O}$ that are separated by an interval (405-kyr eccentricity cycle

122 long) of partial $\delta^{18} \mathrm{O}$ recovery (15). The onset of the OMT is thereby comparable in

123 structure to the EOT (3). A 405-kyr long overall decrease in benthic $\delta^{18} \mathrm{O}$ marks the

124 recovery phase of the OMT.

\section{Ice volume estimates}

127 To better understand the significance of the documented $\delta^{18} \mathrm{O}$ variability on long-term

128 change in the high-latitude climate system, we make a conservative estimate of the

129 minimum contribution of continental ice volume to the Site 1264 benthic $\delta^{18} \mathrm{O}$ signal by

130 assuming that Oligo-Miocene bottom-water temperatures at Site 1264 were never colder

131 than the current temperature of $2.5^{\circ} \mathrm{C}$ and applying an average $\delta^{18} \mathrm{O}$ composition of

132 Oligo-Miocene ice sheets $\left(\delta^{18} \mathrm{O}_{\text {ice }}\right.$ ) of $-42 \%$ VSMOW (see Methods; (16)). These

133 minimum ice volume estimates (Fig. 1) do not fully account for the changing relative

134 contributions of ice volume and deep-sea temperature to the benthic $\delta^{18} \mathrm{O}$ signal over

135 glacial-interglacial cycles. However, they are largely consistent with estimates of

136 glacioeustatic sea level change from the New Jersey shelf (17) and those generated by

137 inverse models of (multi-site composite) $\delta^{18} \mathrm{O}$ records $(12,18)$. These ice volume 
138 estimates and sea level reconstructions strongly suggest that a very large part of the

139 benthic $\delta^{18} \mathrm{O}$ signal is linked to large ice volume changes on Antarctica.

141 Three major new results stand out in the minimum ice-volume calculations on the Site

1421264 benthic $\delta^{18} \mathrm{O}$ record (Fig. 1A). First, excluding the OMT interval, the Oligocene

143 glacials are characterized by larger continental ice-sheet volumes than those of the early

144 Miocene, particularly during the MOGI. Second, across the OMT, Antarctica transitioned

145 from a climate state that was fully deglaciated to one characterized by an ice sheet as

146 large as the present East Antarctic Ice Sheet and back into a fully deglaciated state in less

147 than 1 Myr. Third, many glacial-interglacial cycles in the benthic $\delta^{18} \mathrm{O}$ record are

148 associated with a $\delta^{18} \mathrm{O}_{\mathrm{sw}}$ change of at least $\sim 0.60$ to $0.75 \%$, requiring the waxing and

149 waning of $\sim 21$ to $26 \times 10^{6} \mathrm{~km}^{3}$ of ice, or $\sim 85$ to $110 \%$ of present East Antarctic ice

150 volume, on timescales of $\leq 110 \mathrm{kyr}$.

\section{Sinusoidal glacial-interglacial cycle properties}

153 The 13 Myr-long Oligo-Miocene benthic $\delta^{18} \mathrm{O}$ record from Site 1264 shows distinct

154 cyclicity on astronomical time scales. Wavelet analysis reveals (Figs. 1, S1; (15)) that the

155 amplitude of variability at the $\sim 110$-kyr eccentricity periodicity is particularly

156 pronounced ( $\geq 1.0 \%$ across the larger $\delta^{18} \mathrm{O}$ cycles). The amplitude of the $40-\mathrm{kyr}$ obliquity

157 periodicity is subdued in comparison to published records from other sites, presumably

158 because of the higher sedimentation rates at those sites $(13,19)$. Four relatively short

159 (405 kyr-long) intervals with particularly strong $\sim 110$-kyr-paced $\delta^{18} \mathrm{O}$ variability are also

160 identified in the record (vertical gray bars, Fig. 1), demonstrating a pronounced climate- 
161 cryosphere response to eccentricity-modulated precession of Earth's spin-axis (15). These

162 intervals are contemporaneous with 405-kyr eccentricity maxima during 2.4-Myr

163 eccentricity maxima, specifically 405-kyr Cycles 73, 68, 57 and 49. Thus, while the OMT

164 deserves its status as a major transient Cenozoic event $(1,20)$ because it is a prominent

165 but transient glacial episode that abruptly terminates late Oligocene warming, the

166 amplitude of ice age cycles observed as the climate system emerges from peak glacial

167 OMT conditions is not unique in the Oligo-Miocene. In fact, this recovery phase of the

168 OMT is one of four Oligo-Miocene intervals characterized by particularly high-amplitude

$169 \sim 110-\mathrm{kyr}$ oscillations between glacial and interglacial Antarctic conditions (Fig. 1A). The

170 record from Site 1264 is the first to unequivocally show that the $\sim 2.4-\mathrm{Myr}$ eccentricity

171 cycle paces recurrent episodes of high-amplitude $\sim 110$-kyr variability in benthic $\delta^{18} \mathrm{O}(9$,

172 19) and provides a new global climatic context in which to understand Oligo-Miocene

173 glacial history, carbon cycling $(9,21)$, mid-latitude terrestrial water balance (22) and

174 mammal turnover rates (23) that show similar pacing. The intervals with particularly

175 strong $\sim 110$-kyr cycles are separated by prolonged periods of attenuated $\sim 110$-kyr cycle

176 amplitude, indicating that not all $\sim 2.4-\mathrm{Myr}$ and 405 -kyr eccentricity maxima trigger

177 similar cryospheric responses (Fig. 1). Specifically, 2.4-Myr Eccentricity Cycle 11 in

178 the late Oligocene is not characterized by high-amplitude $\sim 110$-kyr cycles (Fig. 1).

179 Furthermore, no consistent relationship is found between strong $~ 110$-kyr cycles in

180 benthic $\delta^{18} \mathrm{O}$ and the $\sim 1.2-\mathrm{Myr}$ amplitude modulation of obliquity (15). This suggests that

181 some other factor or combination of factors is responsible for the changing response of

182 the climate system to astronomical forcing on $\sim 110$-kyr time scales over the Oligo-

183 Miocene. 
185 We assess the phase-relationships of the tuned $\delta^{18} \mathrm{O}$ data with respect to the main

186 frequencies of orbital eccentricity to track the response times of the Oligo-Miocene

187 climate system (Figs. 1, S2, S3). The benthic $\delta^{18} \mathrm{O}$ record from Site 1264 displays a

188 marked multi-Myr evolution in the phasing of the $\sim 110-\mathrm{kyr}$ cycle relative to eccentricity

189 starting with a $\sim 10$ kyr phase lag during the mid Oligocene, followed by an unstable

190 phase relation at 26 Myr ago and a steady increase in phase that culminates in a 10-15

191 kyr lag at $\sim 19.0$ Myr ago (Fig. S3). The $\sim 95-k y r$ and $\sim 125-k y r$ frequencies show largely

192 independent phase evolutions. On the basis of these data alone, we cannot rule out the

193 possibility that part of the observed structure in the long-term phase evolution arises from

194 changes in the proportional contribution of temperature and ice volume to benthic $\delta^{18} \mathrm{O}$

195 (24). Yet the observed changes in phase are so large $(\sim-10 \mathrm{kyr}$ to $+15 \mathrm{kyr})$ that changes

196 in the response time of Antarctic ice sheets are most likely responsible; large continental

197 ice sheets are the slowest-responding physical component of Earth's climate system and

198 the only mechanism capable of inducing phase lags in deep-sea benthic $\delta^{18} \mathrm{O}$ records of

$199 \sim 10-15 \operatorname{kyr}(25)$. Analysis of phasing suggests that over full glacial-interglacial cycles,

200 the high latitude climate-Antarctic ice sheet system responded more slowly to

201 astronomical pacing during the MOGI ( 28.0-26.3 Myr ago) and early Miocene ( $\lesssim 23$

202 Myr ago), than during either the early Oligocene ( 30.1-28.0 Myr ago) or late Oligocene

203 ( 26.3-23.7 Myr ago).

204

205 Bispectral analysis 
206 To investigate phase coupling between (astronomical) cycles embedded in the Site 1264

207 benthic $\delta^{18} \mathrm{O}$ record, we apply bispectral techniques (26-28). A bispectrum identifies

208 phase-couplings between three frequencies: $f_{1}, f_{2}$ and their sum frequency $f_{1}+f_{2}=f_{3}$.

209 When phase coupled, energy transfers nonlinearly between these frequencies and is

210 redistributed over the spectrum. This results in lower and higher harmonics and in the

211 formation of skewed and/or asymmetric cycle geometries such as those observed in the

$212 \delta^{18} \mathrm{O}$ record. We compare bispectra for two selected time intervals with strong $\sim 110-\mathrm{kyr}$

213 cyclicity (Fig. 2): a mid-Oligocene interval, during 2.4-Myr Eccentricity Cycle 12

214 (28.30-26.30 Myr ago), and an OMT-spanning interval, during 2.4-Myr Eccentricity

215 Cycle 10 (23.54-21.54 Myr ago). A third, early Miocene example is considered in Fig.

216 S5. The bispectra show that during both the mid-Oligocene and the OMT numerous

217 phase-couplings occur with frequencies that include, but are not limited to, astronomical

218 cycles. Most interactions occur between cycles with periodicities close to those of

219 eccentricity (periods of $405, \sim 125$ and $\sim 95 \mathrm{kyr} /$ cycle, equal to frequencies of $2.5,8.0$ and

22010.5 cycles/Myr respectively) that exchange energy among one another and also with

221 higher frequencies. The close proximity of both positive and negative interactions around

222 eccentricity frequencies (Figs. 2, S4) suggests that these frequencies redistribute energy

223 by broadening spectral peaks in $\delta^{18} \mathrm{O}$. This process may explain the observed $\sim 200-\mathrm{kyr}$

224 cycle (15). The main difference between the two selected time intervals is that the OMT

225 bispectrum reveals many more nonlinear interactions (Fig. 2), both positive and negative,

226 which indicates that the climate/cryosphere system responded in a more complex and

227 indirect manner to insolation forcing across the OMT than during the MOGI. This

228 observation may point to the activation of heightened positive feedback mechanisms 
229 across the OMT related to continental ice-sheet growth and decay $(13,29)$, possibly

230 involving the carbon cycle (30) or Antarctic sea ice (31).

231

\section{Non-sinusoidal glacial-interglacial cycle properties}

233 To further understand the nonlinearity in the climate system documented by the bispectra,

234 we assess non-sinusoidal (i.e. non-Gaussian) cycle properties (Figs. 3, S5-S8, see also SI

235 Text). Nonlinearity in climate cycles can be quantified in terms of skewness, asymmetry

236 and kurtosis using standard and higher-order spectral analyses to elucidate the rapidity of

237 climatic transitions (see Methods). The remarkably consistent negative skewness in the

$238 \delta^{18} \mathrm{O}$ record (mean -0.18 , Figs. 3, S8) indicates that Oligo-Miocene glacials were longer

239 in duration than interglacials - a result that is consistent with the late Pleistocene record

240 (Fig. S6; $(27,28,32)$ ). To assess the time spent per cycle in full glacial and full

241 interglacial conditions (in contrast to skewness which records the duration of glacials

242 versus interglacials), we also calculate the evolution of cycle kurtosis through the benthic

$243 \delta^{18} \mathrm{O}$ record. Square-waved (platykurtic) glacial-interglacial cycles are more evident in

244 the Site 1264 record than thin-peaked (leptokurtic) ones, apart from an early Miocene

245 interval between $\sim 21.5$ and 19.0 Myr ago when leptokurtic cycles prevail (Figs. 3, S8).

246 This observation indicates that the Oligo-Miocene climate system generally favored full

247 glacial and full interglacial conditions and transitioned rapidly between those two climate

248 states. We attribute this finding to the operation of well-documented strong positive

249 feedbacks on ice sheet growth and decay $(25,29)$. 
251 To understand the relative rates of ice sheet growth versus decay we quantify cycle

252 asymmetry. While the Site 1264 record shows consistently skewed Oligo-Miocene $\sim 110$ -

253 kyr glacial-interglacial cycles, we document a major change over time in the symmetry of

254 those cycles that is marked by a transition to more asymmetric cycles which began $\sim 23$

255 Myr ago at the OMT. This change represents a shift to a new climatic state characterized

256 by strong 2 .4-Myr pacing of glacial-interglacial asymmetry and is associated with lower

257 atmospheric $\mathrm{CO}_{2}$ levels (Fig. 3; $(6,7)$ ) Asymmetry in the data series is particularly

258 pronounced during 405-kyr Eccentricity Cycles 57 and 49 (at 22.7 and 19.5 Myr ago),

259 which are characterized by distinctly sawtooth-shaped $\sim 110$-kyr cycles, suggesting a

260 causal link between cycle amplitude and asymmetry during the early Miocene, but not

261 during the MOGI. The distinctly asymmetric cycles suggest that the early Miocene

262 Antarctic ice sheets periodically underwent intervals of growth that were prolonged

263 relative to astronomical forcing and then underwent subsequent rapid retreat in a manner

264 akin to the glacial terminations of the late Pleistocene glaciations, in which the large ice

265 sheets of the Northern Hemisphere were major participants $(27,28,32)$. The highly

266 asymmetric (sawtooth) nature of late Pleistocene glacial-interglacial cycles is thought to

267 originate from a positive ice mass-balance that persists through several precession- and

268 obliquity-paced summer insolation maxima. This results in decreased ice-sheet stability

269 and rapid terminations every $\sim 110 \mathrm{kyr}$, once the ablation of the Northern Hemisphere ice

270 sheets increases dramatically in response to the next insolation maximum. The increase in

271 ablation is caused by lowered surface elevation of the ice sheets resulting from crustal

272 sinking and delayed isostatic rebound (33). Similar mechanisms are implied for the large

273 Antarctic ice sheets of the OMT ( $22.5 \mathrm{Myr}$ ago) but it is less clear why the smaller ice 
274 sheets of the early Miocene ( 19.5 Myr ago) would exhibit this distinctly sawtoothed

275 pattern of growth and decay (Fig. 3).

276

277 Climate-cryosphere evolution

278 Analysis of the new $\delta^{18} \mathrm{O}$ record from Site 1264 raises two important questions: (i) Why

279 did Antarctic ice sheets decrease in size after the OMT? (ii) Why was hysteresis (i.e.,

280 glacial-interglacial asymmetry) apparently stronger for both the large OMT and the

281 smaller early Miocene ice sheets than for the large ice sheets of the Oligocene? One

282 explanation for the long-term change in ice volume is that the large glacial ice volumes of

283 the MOGI were possible because of higher topography in West Antarctica (34) that

284 permitted formation of a large terrestrial ice sheet that also buttressed growth of ice

285 sheets on East Antarctica $(25,35)$. In this interpretation, tectonic subsidence and glacial

286 erosion during the late Oligocene caused a shift to a smaller marine-based ice sheet in

287 West Antarctica $(25,35)$, which limited the maximum size of the early Miocene Antarctic

288 ice sheets during peak glacial intervals.

290 The early Miocene ice sheets may have been less responsive to astronomically paced

291 changes in radiative forcing because of colder polar temperatures under lower $\mathrm{CO}_{2}$

292 conditions from $\sim 24$ Myr ago onwards (7) or restriction of ice sheets to regions of East

293 Antarctica above sea level following the late Oligocene subsidence of West Antarctica

$294(25,35)$. Another possibility is that the large ice sheets that characterized the peak

295 glacials of the MOGI underwent rapid major growth and decay because of higher-

296 amplitude glacial-interglacial $\mathrm{CO}_{2}$ changes than during the early Miocene. Such 
297 hypothesized high amplitude changes in $\mathrm{CO}_{2}$ would have had a direct effect on radiative

298 forcing, which in turn would have caused faster feedbacks and a more linear response to

299 eccentricity-modulation of precession. Given that larger ice volumes are to be expected

300 in a climatic state that is characterized by high cycle asymmetry and low atmospheric

$301 \mathrm{CO}_{2}$ concentration, a third possibility is that the conservative calculations substantially

302 underestimate true ice volumes for the early Miocene. Each of these hypotheses can be

303 tested through a combination of scientific drilling on the West Antarctic shelf margin and

304 development of high-resolution $\mathrm{CO}_{2}$ and marine temperature proxy records with

305 astronomical age control. We predict that strong eccentricity-driven $\mathrm{CO}_{2}$ cycles $(\sim 110$,

$306405, \& \sim 2400 \mathrm{kyr}$ ) that are closely in-step with ice volume changes will emerge in proxy

$307 \mathrm{CO}_{2}$ reconstructions for the Oligo-Miocene time interval. Assuming that changes in

308 partitioning of the benthic $\delta^{18} \mathrm{O}$ signal between temperature and ice volume are modest

309 throughout the Oligo-Miocene, the deep-sea $\delta^{18} \mathrm{O}$ record from Site 1264 suggests a clear

310 long-term shift from a more glacial Oligocene to a less glacial early Miocene climate

311 state - a pattern of change not readily reconciled with the long-term decrease in published

$312 \quad \mathrm{CO}_{2}$ records.

313

314 Acknowledgments: We thank David Heslop and Lie-Liang Yang for insightful

315 discussions and assistance. We used samples provided by the Ocean Drilling Program,

316 sponsored by the US National Science Foundation and participating countries under the

317 management of the Joint Oceanographic Institutions. We are greatly indebted to the

318 scientists and supporting staff of ODP Leg 208. This research was made possible by

319 funding of ERC grants 215458 (“GTS-NEXT”, F.J.H.) and 617462 
321 and 821.01.012 (G.R.), NERC grant NE/K014137/1 (P.A.W.), and a Royal Society

322 Wolfson award (P.A.W.).

323

\section{References}

325 1. Zachos JC, Dickens GR, \& Zeebe RE (2008) An early Cenozoic perspective on

326 greenhouse warming and carbon-cycle dynamics. Nature 451(7176):279-283.

327 2. Zachos JC, Breza JR, \& Wise SW (1992) Early Oligocene ice-sheet expansion on

328 Antarctica: Stable isotope and sedimentological evidence from Kerguelen Plateau, 329 southern Indian Ocean. Geology 20:569 - 573.

330 3. Coxall HK, Wilson PA, Pälike H, Lear CH, \& Backman J (2005) Rapid stepwise 331 onset of Antarctic glaciation and deeper calcite compensation in the Pacific $332 \quad$ Ocean. Nature 433(7021):53-57.

333 4. Naish TR, et al. (2001) Orbitally induced oscillations in the East Antarctic ice 334 sheet at the Oligocene/Miocene boundary. Nature 413:719-723.

335 5. Bailey I, et al. (2013) An alternative suggestion for the Pliocene onset of major 336 northern hemisphere glaciation based on the geochemical provenance of North 337 Atlantic Ocean ice-rafted debris. Quaternary Science Reviews 75:181 - 194.

338 6. Beerling DJ \& Royer DL (2011) Convergent Cenozoic $\mathrm{CO}_{2}$ history. Nature $339 \quad$ Geoscience 4:418 - 420.

340 7. Zhang YG, Pagani M, Liu Z, Bohaty S, \& DeConto R (2013) A 40-million-year 341 history of atmospheric $\mathrm{CO}_{2}$. Phil. Trans. R. Soc. A 371. 
342 8. Laskar J, Gastineau M, Delisle J-B, Farrés A, \& Fienga A (2011) Strong chaos

343 induced by close encounters with Ceres and Vesta. Astronomy and Astrophysics

$344 \quad 532($ L4):1-4.

345 9. Pälike H, et al. (2006) The heartbeat of the Oligocene climate system. Science $346 \quad 314: 1894-1898$.

347 10. Wade BS \& Pälike H (2004) Oligocene climate dynamics. Paleoceanography $348 \quad 19(4)$.

349 11. Holbourn A, Kuhnt W, Kochhann KGD, Andersen N, \& Meier KJS (2015)

350 Global perturbation of the carbon cycle at the onset of the Miocene Climatic $351 \quad$ Optimum. Geology.

352 12. Liebrand D, et al. (2011) Antarctic ice sheet and oceanographic response to 353 eccentricity forcing during the early Miocene. Climate of the Past 7:869-880.

354 13. Zachos JC, Shackleton NJ, Revenaugh JS, Palike H, \& Flower BP (2001) Climate 355 response to orbital forcing across the Oligocene-Miocene boundary. Science $356 \quad 292(5515): 274-278$.

357 14. Zachos JC, et al. (2004) Initial Reports: Leg 208. in Proceedings of the Ocean 358 Drilling Program (Ocean Drilling Program).

359 15. Liebrand D, et al. (2016) Cyclostratigraphy and eccentricity tuning of the early $360 \quad$ Oligocene through early Miocene (30.1-17.1 Ma): Cibicides mundulus stable 361 oxygen and carbon isotope records from Walvis Ridge Site 1264. Earth and $362 \quad$ Planetary Science Letters 450:392-405.

363 16. DeConto RM, et al. (2008) Thresholds for Cenozoic bipolar glaciation. Nature $364 \quad 455: 652-656$. 
365 17. Miller KG, et al. (2005) The phanerozoic record of global sea-level change. $366 \quad$ Science 310(5752):1293-1298.

367 18. De Boer B, Van de Wal RSW, Bintanja R, Lourens LJ, \& Tuenter E (2010)

368 Cenozoic global ice-volume and temperature simulations with 1-D ice-sheet 369 models forced by benthic $\delta^{18} \mathrm{O}$ records. Annals of Glaciology 51(55):23-33.

370 19. Pälike H, Frazier J, \& Zachos JC (2006) Extended orbitally forced palaeoclimatic 371

373 20. Beddow HM, Liebrand D, Sluijs A, Wade BS, \& Lourens LJ (2016) Global 374 change across the Oligocene-Miocene Transition: High-resolution stable isotope 375 records from IODP Site U1334 (equatorial Pacific Ocean). Paleoceanography $376 \quad 31: 81-97$

377 21. Valero L, Cabrera L, Sáez A, \& Garcés M (2016) Long-period astronomically378 forced terrestrial carbon sinks. Earth and Planetary Science Letters 444:131-138.

379 22. Valero L, Garcés M, Cabrera L, Costa E, \& Sáez A (2014) 20 Myr of eccentricity 380 paced lacustrine cycles in the Cenozoic Ebro Basin. Earth and Planetary Science $381 \quad$ Letters 408:183-193.

382 23. Van Dam JA, et al. (2006) Long-period astronomical forcing of mammal 383 turnover. Nature 443(7112):687-691.

384 24. Elderfield H, et al. (2012) Evolution of ocean temperature and ice volume through 385 the mid-Pleistocene climate transition. Science 337:704 - 709.

386 25. Gasson E, DeConto RM, Pollard D, \& Levy RH (2016) Dynamic Antarctic ice 387 sheet during the early to mid-Miocene. P Natl Acad Sci USA 113(13):3459-3464. 
388 26. Hasselmann K, Munk W, \& MacDonald G (1963) Bispectra of ocean waves.

389 Proceedings of the Symposium on Time Series Analysis, ed Rosenblatt M (John

$390 \quad$ Wiley), pp 125-139.

391 27. Hagelberg T, Pisias N, \& Elgar S (1991) Linear and nonlinear couplings between

392 orbital forcing and the marine $\delta^{18} \mathrm{O}$ record during the late Neogene.

$393 \quad$ Paleoceanography 6(6):729 - 746.

394 28. King T (1996) Quantifying nonlinearity and geometry in time series of climate.

395 Quaternary Science Reviews 15:247 - 266.

396 29. DeConto RM \& Pollard D (2016) Contribution of Antarctica to past and future $397 \quad$ sea-level rise. Nature 531(7596):591-597.

398 30. Mawbey EM \& Lear CH (2013) Carbon cycle feedbacks during the Oligocene399 Miocene transient glaciation. Geology 41(9):963-966.

400 31. DeConto R, Pollard D, \& Harwood D (2007) Sea ice feedback and Cenozoic 401 evolution of Antarctic climate and ice sheets. Paleoceanography 22(3).

402 32. Lisiecki LE \& Raymo ME (2007) Plio-Pleistocene climate evolution: trends and 403 transitions in glacial cycle dynamics. Quaternary Science Reviews 26(1-2):56-69.

404 33. Abe-Ouchi A, et al. (2013) Insolation-driven 100,000-year glacial cycles and 405 hysteresis of ice-sheet volume. Nature 500:190-194.

406 34. Fretwell P, et al. (2013) Bedmap2: improved ice bed, surface and thickness 407 datasets for Antarctica. Cryosphere 7(1):375-393.

408 35. Levy R, et al. (2016) Antarctic ice sheet sensitivity to atmospheric $\mathrm{CO}_{2}$ variations 409 in the early to mid-Miocene. P Natl Acad Sci USA 113(13):3453-3458. 
410 36. Miller KG, Fairbanks RG, \& Mountain GS (1987) Tertiary Oxygen Isotope

411 Synthesis, Sea Level History, and Continental Margin Erosion. Paleoceanography

$412 \quad 2(1): 1-19$.

413 37. Marchitto TM, et al. (2014) Improved oxygen isotope temperature calibrations for $414 \quad$ cosmopolitan benthic foraminfera. Geochimica et Cosmochimica Acta 130:1 - 11 .

415 38. Schlitzer R (2010) Ocean Data View 4, version 4.3.6, http://odv.awi.de).

416 39. Bohaty SM, Zachos JC, \& Delaney ML (2012) Foraminiferal Mg/Ca evidence for 417 Southern Ocean cooling across the Eocene-Oligocene transition. Earth and $418 \quad$ Planetary Science Letters 317-318:251-261.

419 40. Petersen SV \& Schrag DP (2015) Antarctic ice growth before and after the 420 Eocene-Oligocene transition: New estimates from clumped isotope 421 paleothermometry. Paleoceanography 30:1305-1317.

422 41. Bamber JL, Layberry RL, \& Gogineni S (2001) A new ice thickness and bed data 423 set for the Greenland ice sheet 1. Measurement, data reduction, and errors. $J$ 424 Geophys Res-Atmos 106(D24):33773-33780.

425 42. Charette MA \& Smith WHF (2010) The Volume of Earth's Ocean. Oceanography $426 \quad 23(2): 112-114$.

427 43. Paillard D, Labeyrie L, \& Yiou P (1996) AnalySeries, Macintosh program 428 performs time-series analysis. EOS Transactions $A G U$ 77(39):379.

429 44. Beddow HM, et al. (2016) Early to middle Miocene climate evolution: benthic 430 oxygen and carbon isotope records from Walvis Ridge Site 1264. Orbital forcing 431 and climate response; astronomically-tuned age models and stable isotope 
records for the Oligocene-Miocene, ed Beddow HM (Utrecht University, $433 \quad$ Utrecht), Vol PhD.

434 45. Chaudhuri P \& Marron JS (1999) SiZer for exploration of structures in curves. $435 \quad$ Journal of the American Statistical Association 94(447):807 - 823.

436 46. Herbers THC, Russnogle NR, \& Elgar S (2000) Spectral energy balance of 437 breaking waves within the surf zone. Journal of Physical Oceanography 30:2723 $438-2737$.

439 47. Elgar S (1987) Relationships involving third moments and bispectra of a 440 harmonic process. IEEE Transactions of Acoustics, Speech, and Signal $441 \quad$ Processing ASSP-35(12):1725 - 1726.

442 48. De Bakker ATM, Herbers THC, Smit PB, Tissier MFS, \& Ruessink BG (2015) 443 Nonlinear infragravity-wave interactions on a gently sloping laboratory beach. $444 \quad$ Journal of Physical Oceanography 45:589 - 605.

445 49. Doering JC \& Bowen AJ (1995) Parametrization of orbital velocity asymmetries 446 of shoaling and breaking waves using bispectral analysis. Coastal Engineering $447 \quad 26: 15-33$.

448 50. Kennedy AB, Chen Q, Kirby JT, \& Dalrymple RA (2000) Boussinesq modeling 449 of wave transformation, breaking, and runup. I:1d. Journal of waterway, port, $450 \quad$ coastal, and ocean engineering:39-47.

451 51. Pearson K (1905) Skew variation, a rejoinder. Biometrika IV:169-212.

452 52. Herbert TD (1994) Reading orbital signals distorted by sedimentation: models and 453 examples. Spec. Publs Int. Ass. Sediment 19:483-507. 
454 53. Bard E (2001) Paleoceanographic implications of the difference in deep-sea 455 sediment mixing between large and fine particles. Paleoceanography 16(2):235 456239.

457 54. Lisiecki LE \& Raymo ME (2005) A Pliocene-Pleistocene stack of 57 globally $458 \quad$ distributed benthic $\delta^{18} \mathrm{O}$ records. Paleoceanography 20.

$460 \quad$ Figure Legends

461 Fig. 1. High-latitude climate/cryosphere evolution during the Oligo-Miocene and 462 sinusoidal glacial-interglacial cycle properties. (A) Benthic foraminiferal (Cibicides 463 mundulus) $\delta^{18} \mathrm{O}$ record from ODP Site 1264 (gray line; (15)) and SiZer smooth (blue line, 464 see Methods). Minimum ice volume contribution (lilac area, right axis) to the benthic $465 \quad \delta^{18} \mathrm{O}$ record calculated relative to all values exceeding $1.65 \%$ (left axis, see Methods).

466 Dashed red line represents the contribution to benthic $\delta^{18} \mathrm{O}$ of a present day-sized East 467 Antarctic Ice Sheet $\left(\delta^{18} \mathrm{O}_{\text {ice }}=-42 \%\right)$. (B-D) Sinusoidal glacial-interglacial cycle 468 properties. (B) Wavelet analysis of the Site 1264 benthic $\delta^{18} \mathrm{O}$ record. White dashed lines 469 represent the $\sim 95$ - and $\sim 125$-kyr eccentricity periodicities, respectively. (C) Filter of the 470 Site 1264 benthic $\delta^{18} \mathrm{O}$ record centered around the $\sim 110$-kyr periodicity (dark blue line) 471 and its amplitude modulation (light blue line and area), compared to those of eccentricity 472 (gray lines and area). The filter values are proportional to the eccentricity (left axis) and 473 the VPDB scale (right axis), respectively. In the background (light brown line and area) 474 the $\sim 2.4-\mathrm{Myr}$ component of Earth's orbital eccentricity is shown $(+0.02$, brown bold italic 475 numbers). (D) Phase-evolution of the $\sim 125$-kyr (dark blue area, green dots) $\sim 95-\mathrm{kyr}$ 476 (purple area, brown dots) and combined (including intermediate frequencies) $\sim 110-\mathrm{kyr}$ 
477 (light blue area, orange dots) cycle to eccentricity, which show independent evolutions.

478 Vertical gray bars represent 405-kyr Eccentricity Cycles 49, 57, 68 and 73 (dark gray

479 italic numbers), characterized by exceptionally strong $\sim 110$-kyr responses in benthic $\delta^{18} \mathrm{O}$ $480 \quad$ (Fig. 3; (15)).

481

482 Fig. 2. Bispectra assessing phase coupling and energy transfers between frequencies

483 in the $\delta^{18} \mathrm{O}$ data. Bispectral analyses on benthic $\delta^{18} \mathrm{O}$ across two, 2-Myr long windows

484 with strong 110-kyr cycles (see also Fig. S4). (A) Bispectrum across the OMT interval,

485 during 2.4-Myr Eccentricity Cycle 10 (23.54-21.54 Myr ago). (B) Bispectrum across

486 the MOGI, during 2.4-Myr Eccentricity Cycle 12 (28.30-26.30 Myr ago). The colors of

487 the bispectrum show the direction of the energy transfers. The intensity of the colors is

488 indicative of the magnitude of energy transfers (see Methods). Red indicates a transfer of

489 spectral power from two frequencies $f_{1}$ (see $\mathrm{x}$-axes) and $f_{2}$ (see y-axes), to frequency $f_{3}\left(f_{1}\right.$

$490+f_{2}=f_{3}$ ). In contrast, blue represents a gain of spectral power at frequencies $f_{1}$ and $f_{2}$,

491 from frequency $f_{3}$. Gray lines reflect the main astronomical frequencies of eccentricity,

492 obliquity and precession.

493

494 Fig. 3. Non-sinusoidal glacial-interglacial cycle properties. (A) Atmospheric $\mathrm{CO}_{2}$

495 proxy estimates for the Oligo-Miocene and their long-term smooths (turquoise line and

496 area, see Methods) through the reconstructed values and their maximum and minimum

497 error estimates (black error bars). Gray diamonds represent phytoplankton $\mathrm{CO}_{2}$ estimates,

498 yellow squares are based on stomata, and purple-red triangles represent $\mathrm{CO}_{2}$ estimates

499 based on paleosols $(6,7)$. Multiplication factors on the right refer to pre-industrial (p.-i.) 
$500 \mathrm{CO}_{2}$ concentrations of $278 \mathrm{ppm}$. CE stands for Common Era. (B-E) Four 405-kyr long

501 intervals with exceptionally strong $\sim 110-\mathrm{kyr}$ cycles in benthic $\delta^{18} \mathrm{O}$, plotted against

502 eccentricity and its $\sim 2.4-\mathrm{Myr}$ component (+0.02). These intervals occur during (B) the

503 early Miocene, contemporaneous with 405-kyr Eccentricity Cycle 49, (C) the Oligo-

504 Miocene transition, Cycle 57, (D) the mid-Oligocene, Cycle 68, and (E) the early

505 Oligocene, Cycle 73 (white italic numbers). For panels (B-E) only: long ticks on the age-

506 axis indicate $500 \mathrm{kyr}$ steps and short ticks $100 \mathrm{kyr}$ steps. (F-H) Non-sinusoidal glacial-

507 interglacial cycle properties. (F) Skewness, (G) Asymmetry, and (H) Kurtosis of the Site

5081264 benthic $\delta^{18} \mathrm{O}$ record quantified over a 2-Myr long sliding window using standard

509 (turquoise circles) and bispectral (purple-pink triangles) methods (see Methods). The

510 colored areas indicate the $2 \sigma$ upper and lower ranges of asymmetry. (I) Earth's orbital

511 eccentricity ( 8 ) and its $\sim 2.4-$ Myr component ( +0.02 , brown bold italic). Vertical gray bars

512 as in Fig. 1. To the right of panels F-H the corresponding cycle shapes are depicted and

513 the direction of time is indicated; ig = interglacial, $\mathrm{g}=$ glacial. 


\section{Supporting Information}

\section{Materials and Methods:}

518 All data reported in this paper are available online. Go to: www.pangaea.de, and search

519 for ref. (15), or follow the link: https://doi.pangaea.de/10.1594/PANGAEA.862589.

521 Ice volume calculations. To obtain conservative minimum estimates of continental ice

522 volume (36) across the Oligo-Miocene study interval, we calculated a Cibicides $\delta^{18} \mathrm{O}$

$523\left(\delta^{18} \mathrm{O}_{C i b}\right)$ value from equation 9 of (37) using (i) the modern Site 1264 bottom-water

524 temperatures of $\sim 2.5{ }^{\circ} \mathrm{C}(38)$ and (ii) an 'ice-free' seawater $\delta^{18} \mathrm{O}\left(\delta^{18} \mathrm{O}_{\text {sw }}\right)$ value of

$525-1.05 \%$ vSMOW $(39,40)$. This gives a $\delta^{18} \mathrm{O}_{C i b}$ value of $1.65 \%$ VPDB, indicating that

526 values $\geq 1.65 \%$ o reflect a change in $\delta^{18} \mathrm{O}_{\text {sw }}$ and, hence, a contribution from land ice to the

$527 \delta^{18} \mathrm{O}_{C i b}$ signal, presuming that Oligo-Miocene deep-water temperatures at Site 1264 never

528 cooled below modern-day temperatures. To estimate the minimum Oligo-Miocene land

529 ice volumes, we applied an ice-free ocean volume of $\sim 1.3574 \times 10^{9} \mathrm{~km}^{3}(34,41,42)$ and

530 used a modeled average $\delta^{18} \mathrm{O}$ value of Oligo-Miocene ice sheets of -42\%o VSMOW (16),

531 which yields $\sim 3.8$ million $\mathrm{km}^{3}$ of ice per $0.1 \%$ change in seawater $\delta^{18} \mathrm{O}$. This approach

532 does not account for decreasing $\delta^{18} \mathrm{O}_{\text {ice }}$ through the glacial cycle as the ice sheet becomes

533 larger and higher in elevation. But state-of-the-art ice sheet models show that once a large

534 Antarctic ice sheet is established, the average $\delta^{18} \mathrm{O}_{\text {ice }}$ must have been quite low ( -39 to

$535-48 \% ;(25))$. If we assume that $\delta^{18} \mathrm{O}_{\text {ice }}$ was higher than $-40 \%$, calculated ice volumes are

536 unrealistically large. These ice volume estimates are calculated to show that the ice-

537 volume component of the benthic $\delta^{18} \mathrm{O}$ record must have been large and that the 
538 sinusoidal and non-sinusoidal cycle properties that we quantify are most likely related to

539 Antarctic ice sheet dynamics. We note that the cycle properties, or their long-term

540 evolution, may partially reflect changing relative contributions of temperature and ice

541 volume to benthic $\delta^{18} \mathrm{O}$. Both the Gaussian and the non-Gaussian statistics are applied to

542 the benthic $\delta^{18} \mathrm{O}$ record and are thus independent from the exact amount of ice volume

543 contribution to benthic $\delta^{18} \mathrm{O}$.

545 Sinusoidal cycle properties. All data were resampled at $2.5 \mathrm{kyr}$ and for $\mathrm{CaCO}_{3}$ est. and

$546 \delta^{18} \mathrm{O}$ periodicities $>1 \mathrm{Myr}$ were removed using a notch filter (frequency $=0.0$ cycles $/ \mathrm{Myr}$,

547 bandwidth $=1.0$ cycle/Myr) prior to statistical analyses (43). To calculate phases and

548 non-sinusoidal cycle shapes between 18.1 and $17.1 \mathrm{Myr}$ ago, the $\mathrm{CaCO}_{3}$ est. and $\delta^{18} \mathrm{O}$

549 data from (44) between 17.1 and 16.1 Myr ago were used, as 2-Myr windows were

550 required to perform these statistical analyses. The time-frequency transforms of $\delta^{18} \mathrm{O}$

551 were computed using an adaptation of a wavelet script (Figs. S1, S2; (15)), and for the

552 wavelet analysis only, periodicities greater than $200 \mathrm{kyr}$ were removed from the $\delta^{18} \mathrm{O}$

553 record using a notch filter (43). Gaussian filtering of the $\sim 110$-kyr component of the $\delta^{18} \mathrm{O}$

554 record and a Hilbert transform of the filtered data were calculated to compute the $\sim 110$ -

555 kyr amplitude modulation (frequencies between 6.4 and 12.4 cycles/Myr for Fig. 1b;

556 frequency $=9.4$ cycles $/ \mathrm{Myr}$, bandwidth $=3.0$ cycles $/$ Myr for Fig. S1b). Phase

557 calculations of $\mathrm{CaCO}_{3}$ est. and $\delta^{18} \mathrm{O}$ relative to eccentricity were calculated across 2-Myr

558 windows with 250-kyr time steps through Blackman-Tukey cross-spectral analysis (43)

559 (Figs. S2, S3). Linear trends were removed, the data were pre-whitened, normalized, and

$56095 \%$ confidence levels on the error bars were computed. This resulted in a frequency 
561 resolution of 0.1 cycles/Myr. The frequency bandwidths of 2.2-2.7, 7.4-10.8, 7.4-8.3,

562 and 9.8-10.8 cycles/Myr were used to compute phases for the 405-kyr, $\sim 110-\mathrm{kyr}, \sim 125-$

563 kyr and $\sim 95$-kyr components, respectively. When coherent, maximum, average and

564 minimum values were selected within these frequency bandwidths to yield phases and

565 their 95\% error estimates. Phase estimates are not depicted if none of the frequencies

566 within a bandwidth was coherent. Smooths were taken of the benthic $\delta^{18} \mathrm{O}$ record, the

567 atmospheric $\mathrm{CO}_{2}$ data $(6,7)$ and the non-sinusoidal cycle properties using SiZer

568 (significant zero crossings of derivatives); a statistical method that extracts the structures

569 in curves (Figs. 1, 3, Figs. S6-S8; (45)).

571 Bispectral analysis. The bispectrum assesses coupling and energy transfers between

572 frequencies within a single time-series. The bispectrum is defined (26) as $B_{f_{1}, f_{2}}=E\left[A_{f_{1}}\right.$

$573 A_{f_{2}} A_{f_{1}+f_{2}}^{*}$, where $E[]$ is the ensemble average of the triple product of complex Fourier

574 coefficients $A$ at the frequencies $f_{1}, f_{2}$, and their $\operatorname{sum} f_{1}+f_{2}$, and the asterisk indicates

575 complex conjugation. The imaginary part of the bispectrum is linked to energy transfers

576 (46) and is therefore shown in Figs. 2 and S4. Oligo-Miocene bispectral settings were:

577 resampling resolution $=2.5 \mathrm{kyr}$, window length $=2 \mathrm{Myr}$, step-size $=0.1 \mathrm{Myr}$, blocks $=8$,

578 block length $=1 \mathrm{Myr}$, degrees of freedom $=16$, frequency resolution $=0.001 \mathrm{cycles} / \mathrm{kyr}$

579 (Fig. 2, Figs. S4, S6-S8). Plio-Pleistocene bispectra were calculated to extract

580 geometries, applying the following settings (after $(27,28))$ : resampling resolution $=2.5$

581 kyr, window length $=1 \mathrm{Myr}$, step-size $=0.1 \mathrm{Myr}$, no blocks, degrees of freedom $=2$,

582 frequency resolution $=0.001$ cycles/kyr (Fig. S5). The colors in the bispectral plots (Fig

583 2, Ext. Data Fig. 4) range from $1 \times 10^{-5}$ to $-1 \times 10^{-5}$. Rare values exceeding this range 
584 were set to match these maximum and minimum values to scale the color gradient to the

585 part of the bispectrum where dominant interactions occur. In addition to couplings near

586 eccentricity frequencies (see main text, $f_{\text {ecc. }}=2.5 \& \approx 10.0$ cycles/Myr), we observe some

587 couplings between eccentricity and obliquity $\left(f_{\text {obl. }}=25.0\right.$ cycles $\left./ \mathrm{Myr}\right)$, which are

588 indicated by; for example, the positive interactions at $B(25.0,8.0)$ cycles/Myr in the mid-

589 Oligocene and $B(25.0,10.5)$ cycles/Myr in the OMT interval, where energy is transferred

590 to $f_{3}=33.0$ and 35.5 cycles $/ \operatorname{Myr}(\sim 29 \mathrm{kyr} / \mathrm{cycle})$, respectively. Precession $\left(f_{\text {prec. }} \approx 50.0\right.$

591 cycles/Myr) and obliquity are poorly expressed in the benthic $\delta^{18} \mathrm{O}$ record of Site 1264

592 (15), which may explain their weaker definition in interactions (Fig. S4).

594 Non-sinusoidal cycle properties. Quantifying deviations from sinusoidality provides an 595 objective way to describe cycle shapes $(27,28)$ or wave-forms $(47)$. Walvis Ridge Site

5961264 was tuned using one tie-point every $\sim 125 \mathrm{kyr}$ on average (15) and the cycle shapes

597 of individual $\sim 110$-kyr cycles are therefore unaffected by the tuning approach. We

598 calculate skewness, asymmetry and kurtosis of eccentricity, $\mathrm{CaCO}_{3}$ est. and benthic $\delta^{18} \mathrm{O}$

599 cycles across a 2-Myr sliding window (step-size $0.1 \mathrm{Myr}$ ) to track the evolving geometry

600 of the cycles with the highest variance (i.e. the $\sim 110$-kyr cycles). This 2 -Myr sliding

601 window smooths the signal and may explain the gradual onset of asymmetry already at

$60224 \mathrm{Myr}$ ago. We note that non-sinusoidal cycle properties are not frequency specific, as

603 harmonics between multiple frequencies are needed to distort a sine-shaped cycle. They

604 can, however, be attributed to frequency-bandwidths (48). Skewness and asymmetry are

605 quantified using both standard and bispectral methods (47), to ascertain the

606 reproducibility of the outcome. Kurtosis is quantified using the standard method only, as 
607 no trispectra were calculated. The $2 \sigma$ upper and lower boundary error-ranges, calculated

608 using a 2-Myr sliding window, were added to the long-term SiZer smooths of the

609 (combined) geometry quantifications. Skewness is determined (49) as $S k(x)=$

$610 \frac{\left\langle(x-\bar{x})^{3}\right\rangle}{\left\langle(x-\bar{x})^{2}\right\rangle^{3 / 2}}$, where the overbar indicates the mean value and where $<>$ is the time

611 averaging operator. Asymmetry is determined (50) as $A s(x)=\frac{\left\langle H^{3}(x-\bar{x})\right\rangle}{\left\langle(x-\bar{x})^{2}\right\rangle^{3 / 2}}$, where $H$ is the

612 Hilbert transform. Kurtosis is defined (51) as $k(x)=\frac{\left\langle(x-\bar{x})^{4}\right\rangle}{\left\langle(x-\bar{x})^{2}\right\rangle^{2}}-3$. We extract skewness

613 and asymmetry from the bispectrum following Eq. 3 of (47): $\operatorname{Sk}(x)+i A s(x)=$

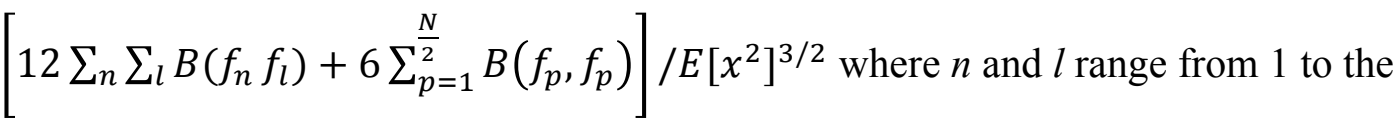

615 Nyquist frequency $\mathrm{N}$, with $n>l$ and $n+l \leq N$. We note that not many studies since the

616 pioneering work of $(27,28)$ on the late Pleistocene records, more recently reproduced

617 using different statistical methods (32), have quantified non-sinusoidal glacial-interglacial

618 cycle properties (such as sawtoothness). Most cyclostratigraphic studies have not

619 commented on the non-sinusoidality of climate cycles or described these properties

620 qualitatively.

622 SI Text:

623 Exploring potential cycle-shape distortion. A number of processes may act to distort

624 the geometry of a glacial-interglacial signal recorded in marine sediments (52). To test

625 for cycle-shape distortion in the stratigraphic domain caused by e.g. coring disturbances

626 and/or (cyclic) changes in sedimentation rates, we computed the non-sinusoidal cycle

627 properties of the $\mathrm{X}$-ray fluorescence core scanning-derived $\mathrm{CaCO}_{3}$ estimate tuning-signal

628 curve (15) and compare these results to the non-sinusoidal cycle properties of the benthic 
$629 \delta^{18} \mathrm{O}$ record to evaluate whether the geometries in each of these records are independent

630 from each other. Both the $\mathrm{CaCO}_{3}$ est. and $\delta^{18} \mathrm{O}$ records reveal strong cyclicity on

631 eccentricity periodicities and therefore we also compare their geometries to those of the

632 eccentricity tuning-target curve (8).

633

634 We note that the eccentricity solution, analyzed over a 2-Myr sliding window, has

635 positive skewness, no asymmetry, and (overall) strong negative kurtosis (Fig. S6).

636 Positive skewness for eccentricity over this window length is a counterintuitive result

637 because individual $\sim 110-k y r$ cycles are characterized by clear negative skewness. The

$638 \mathrm{CaCO}_{3}$ record shows an interval between $\sim 24-18 \mathrm{Myr}$ ago with positive skewness, which

639 is preceded and followed by intervals between $\sim 30-24$ and 18-17 Myr ago with negative

640 skewness (Fig. S7). Asymmetry of $\mathrm{CaCO}_{3}$ est. does not show significant trends or offsets

641 from zero. Kurtosis of $\mathrm{CaCO}_{3}$ est. indicates mostly leptokurtic cycle shapes. The benthic

$642 \delta^{18} \mathrm{O}$ record from Site 1264, also analyzed over 2-Myr long windows, has very

643 comparable skewness to eccentricity (Fig. S8). However, asymmetry and kurtosis show

644 long-term trends independent from eccentricity. Leptokurtic cycles in $\mathrm{CaCO}_{3}$ strongly

645 contrast the platykurtic cycles found in eccentricity and (generally) in benthic $\delta^{18} \mathrm{O}$.

646 Overall, geometries of eccentricity (tuning target), $\mathrm{CaCO}_{3}$ est. (tuning signal) and benthic

$647 \quad \delta^{18} \mathrm{O}$ (climate proxy record) are largely independent from each other.

649 The inverse and (assumed) in-phase relationship between the $\mathrm{CaCO}_{3}$ record and

650 eccentricity (15) (where $\mathrm{CaCO}_{3}$ maxima correspond to eccentricity minima) and the

651 evolution of skewness, suggest (52) that the sediments at Site 1264 result from a 
652 productivity-dominated oceanographic setting, despite long-term trends in absolute

653 values that may reflect a secondary influence of dissolution. Further evidence that the

654 control of dissolution on $\mathrm{CaCO}_{3}$ cycle shape during the Oligocene was smaller than that

655 of productivity comes from the continuously high $\mathrm{CaCO}_{3}$ values, and from the fact that

656 Site 1264, at 2000-2200 meters paleo-water depth, was positioned well above the calcite

657 compensation depth and lysocline throughout the entire Oligo-Miocene (14). We consider

658 the dilution component by terrestrial input to be of a lesser influence on the preserved

659 cycle shapes at Site 1264, as it is positioned far away from land. Physical, grain-size

660 dependent, diffusion-like processes and bioturbation smooth the higher frequency

661 paleoclimate signals in the natural archive (53). However, this probably did not affect

662 cycle geometry in a preferential direction. Similarity in patterns between X-ray

663 fluorescence core scanning records of overlapping intervals from both drill-holes (15)

664 also rules out a significant effect of drilling disturbances on the deformation of specific

665 intervals.

666

667 SI Figure Legends:

668 Fig. S1. Three-dimensional wavelet of $\delta^{18} \mathrm{O}$. Wavelet analysis of the Site 1264 benthic

$669 \delta^{18} \mathrm{O}$ record (21). Frequencies lower than 5 cycles/Myr (i.e. periodicities higher than 200

$670 \mathrm{kyr} / \mathrm{cycle}$ ) have been removed to emphasize the power on the $\sim 10$ cycles/Myr frequency

671 ( 110-kyr periodicity).

672

673 Fig. S2. Phase evolution of $\mathrm{CaCO}_{3}$ est. with respect to eccentricity. (A) Phase-

674 evolution of the $405-\mathrm{kyr}$ cycle in the Site $1264 \mathrm{CaCO}_{3}$ est. record to that of eccentricity. 
675 (B) Phase-evolution of the $\sim 110-$ kyr cycle to eccentricity. (C) Phase-evolutions of the

$676 \sim 125$-kyr and $\sim 95$-kyr cycles to eccentricity. The $\sim 110-\mathrm{kyr}$ cycle of $\mathrm{CaCO}_{3}$ est. (panel B)

677 is continuously coherent and in-phase within the $95 \%$ confidence level (i.e. $\pm 5 \mathrm{kyr}$ of in-

678 phase) with eccentricity, consistent with tuning-assumptions used (15). All further phase

679 calculations (panels A and C this Fig., Fig. S3) are derived from this phase-assumption.

680 Error bars represent the 95\% Blackman-Tukey cross-spectral analysis confidence

681 intervals. Phase calculations are only shown when coherent. Vertical gray bars as in Fig. 6821.

683

684 Fig. S3. Phase evolution of $\delta^{18} \mathrm{O}$ with respect to eccentricity. (A) Phase-evolution of 685 the $405-\mathrm{kyr}$ cycle in the Site 1264 benthic $\delta^{18} \mathrm{O}$ record to that of eccentricity. (B) Phase686 evolution of the $\sim 110$-kyr cycle to eccentricity. (C) Phase-evolutions of the $\sim 125$-kyr and $687 \sim 95-\mathrm{kyr}$ cycles to eccentricity, which show independent evolutions. Error bars represent 688 the $95 \%$ Blackman-Tukey cross-spectral analysis confidence intervals. Phase calculations 689 are only shown when coherent. Vertical gray bars as in Fig. 1.

691 Fig. S4. Bispectra assessing phase coupling and energy transfers between

692 frequencies in the $\delta^{18} \mathbf{O}$ data. Bispectral results over three 2-Myr long intervals that 693 correspond to (A) 2.4-Myr Eccentricity Cycle 9 (21.10 - 19.10 Myr ago, (B) Cycle 10

694 (23.54-21.54 Myr ago) and (C) Cycle 12 (28.30-26.30 Myr ago, see Methods). Gray

695 lines reflect the main astronomical frequencies of eccentricity, obliquity and precession.

696 The two panels of Fig. 2 in the main document are reproduced here (B and C) and

697 expanded to include the interactions with the precession frequencies. 
699 Fig. S5. Proof of methods in quantifying non-sinusoidal cycle properties. (A) Original

700 skewness and asymmetry calculations on Plio-Pleistocene benthic and planktic $\delta{ }^{18} \mathrm{O}$

701 records (27). (B) Reproducing the results of (27) on the Plio-Pleistocene LR04 benthic

$702 \delta^{18} \mathrm{O}$ stack (54). Comparable results have been obtained using a different method (32).

703 Triangles show asymmetry and circles show skewness. Turquoise indicates the standard

704 method and purple-pink represents the bispectral method. Time (Ma) equates to Age

705 (Myr ago).

706

707 Fig. S6. Non-sinusoidal cycle properties of eccentricity. (A) Orbital eccentricity (8),

708 and (B) its skewness, (C) asymmetry, and (D) kurtosis, calculated across a 2-Myr sliding

709 window using standard (turquoise circles) and bispectral methods (purple-pink triangles).

710 An unexplained, small offset in skewness (panel A) is observed between values

711 calculated using the standard and bispectral methods. Vertical gray bars as in Fig. 1.

712

713 Fig. S7 Non-sinusoidal cycle properties of $\mathbf{C a C O}_{3}$ estimate record. (A) $\mathrm{CaCO}_{3}$ est.

714 from Site 1264, and (B) its skewness, (C) asymmetry, and (D) kurtosis, calculated across

715 a 2-Myr sliding window using standard (turquoise circles) and bispectral methods

716 (purple-pink triangles). Seven prominent, decimeter-thick chalk-layers are removed from

717 the Oligocene part of the record prior to the quantification of non-sinusoidal cycle

718 properties as these layers distort the background cyclicity. Vertical gray bars as in Fig. 1. 
720 Fig. S8. Sinusoidal and non-sinusoidal cycle properties of benthic $\delta^{18} \mathrm{O}$. (A)

721 Atmospheric $\mathrm{CO}_{2}$ proxy estimates for the Oligo-Miocene and their long-term smooths

722 (turquoise line and area, see Methods) through the reconstructed values and their

723 maximum and minimum error estimates (black error bars). Gray diamonds represent

724 phytoplankton $\mathrm{CO}_{2}$ estimates, yellow squares are based on stomata and purple-red

725 triangles represent $\mathrm{CO}_{2}$ estimates based on paleosols $(6,7)$. Multiplication factors on the

726 right refer to pre-industrial (p.-i.) $\mathrm{CO}_{2}$ concentrations of $278 \mathrm{ppm}$. CE stands for

727 Common Era. (B) Benthic foraminiferal $\delta^{18} \mathrm{O}$ record from Site 1264, Walvis Ridge. (C)

728 Earth's orbital eccentricity (8) and its $\sim 2.4-\mathrm{Myr}$ component $(+0.02$, brown bold italic

729 cycle numbers). (D-F) Sinusoidal cycle properties. (D) Wavelet analysis of the Site 1264

730 benthic $\delta^{18} \mathrm{O}$ record. Frequencies lower than 5 cycles/Myr (i.e. periodicities higher than

$731200 \mathrm{kyr} / \mathrm{cycle}$ ) have been removed to emphasize the power on the $\sim 10 \mathrm{cycles} / \mathrm{Myr}$

732 frequency ( 110-kyr periodicity). (E) Gaussian filters (lines) and amplitude modulations

733 (areas) of the combined $\sim 95 \mathrm{kyr}$ and $\sim 125 \mathrm{kyr}$ periodicities (centered around $\sim 110 \mathrm{kyr}$ ) of

734 the eccentricity solution (gray) and detrended benthic $\delta^{18} \mathrm{O}$ data (blue). (F) Blackman-

735 Tukey phase calculations across a 2-Myr sliding window (step size 0.25 Myr). 95\%

736 significance estimates are indicated. (G-I) Non-sinusoidal cycle properties. (F)

737 Skewness, (H) asymmetry, and (I) kurtosis, calculated using standard (turquoise circles)

738 and bispectral methods (purple-pink triangles). Corresponding cycle shapes are indicated

739 on the right. ig = interglacial, $\mathrm{g}=$ glacial. Background areas indicate the $2 \sigma$ upper and

740 lower ranges of these non-sinusoidal cycle properties. (J-M) Four recurrent intervals

741 during the Oligo-Miocene characterized by high-amplitude $\sim 110$-kyr cyclicity in benthic

$742 \delta^{18} \mathrm{O}$ (dark blue lines), compared to eccentricity (gray areas) and its $\sim 2.4-\mathrm{Myr}$ component 
743 (light brown areas). (J) The early Oligocene, contemporaneous with 405-kyr Eccentricity

744 Cycle 73. (K) The mid-Oligocene, contemporaneous with Cycle 68. (L) The Oligo-

745 Miocene transition, contemporaneous with Cycle 57. (M) The early Miocene,

746 contemporaneous with Cycle 49. White numbers correspond to 405-kyr eccentricity

747 cycles. To the right of panels B-I the Antarctic ice sheet and eccentricity conditions are

748 suggested, and corresponding cycle shapes are depicted. Arrow indicates the direction of

749 time. ig $=$ interglacial, $\mathrm{g}=$ glacial. Vertical gray bars as in Fig. 1. 


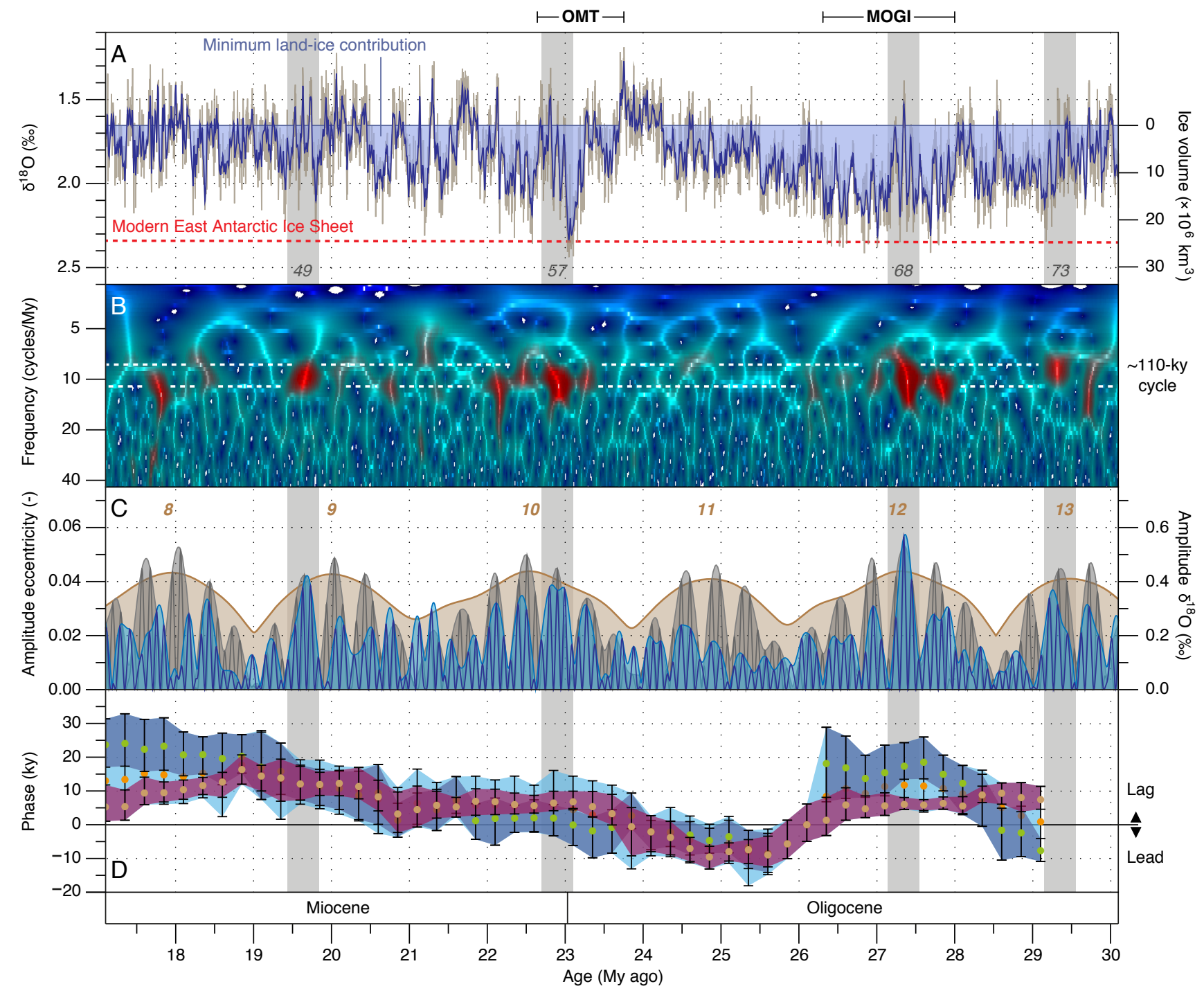




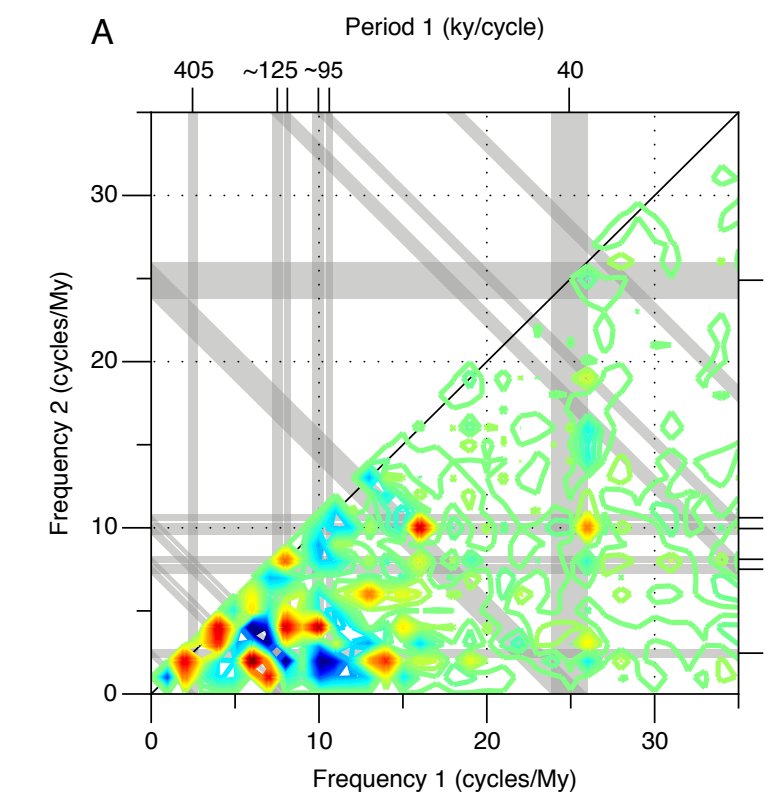

B Period 1 (ky/cycle)

$405 \sim 125 \sim 95 \quad 40$
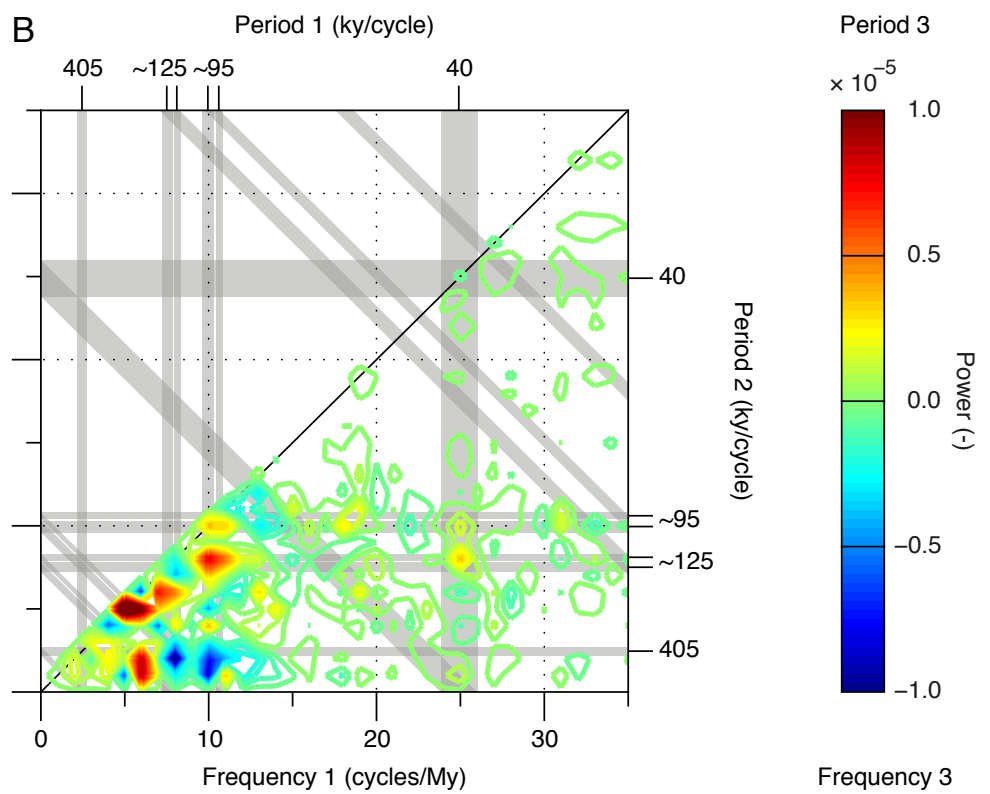

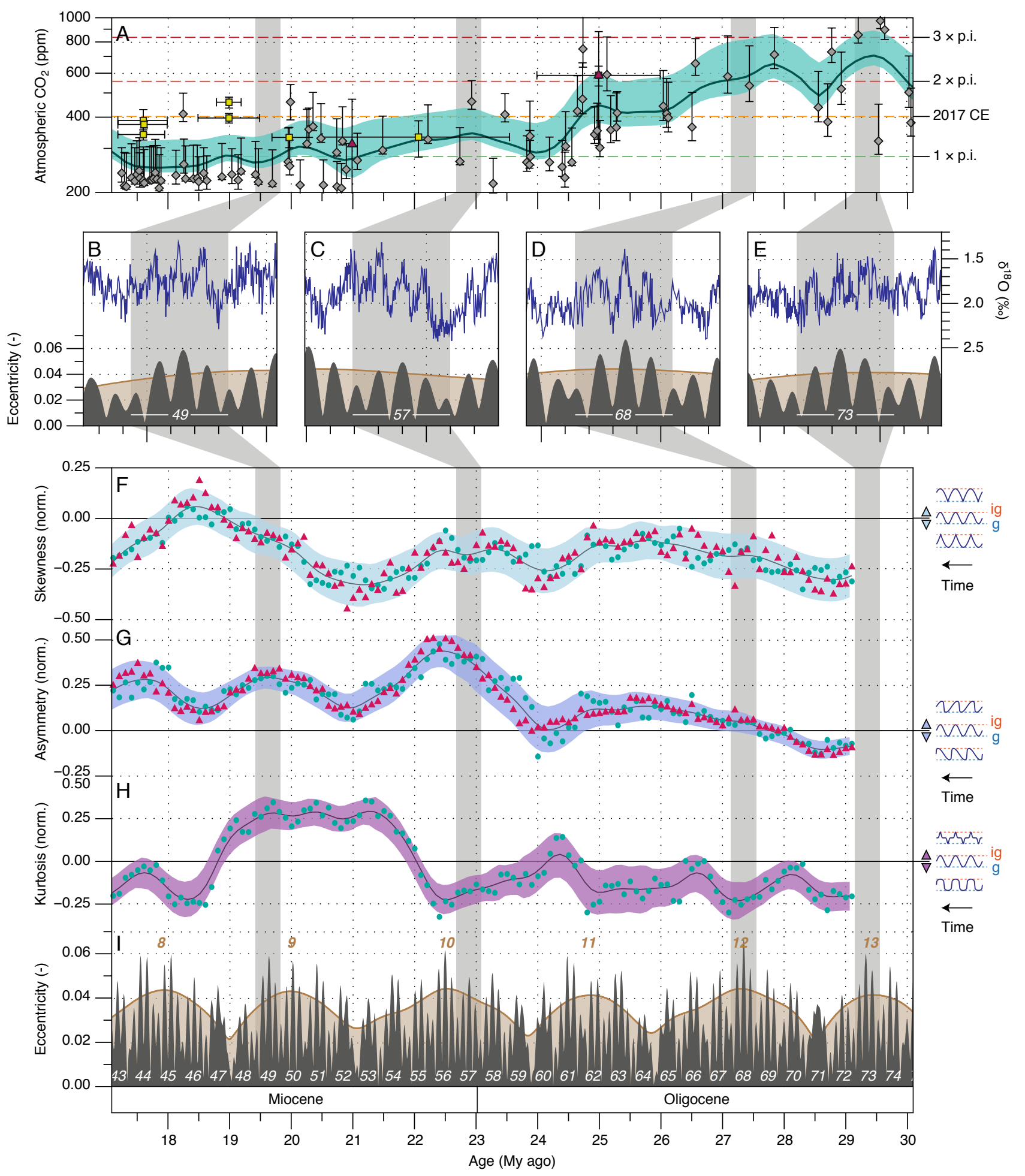


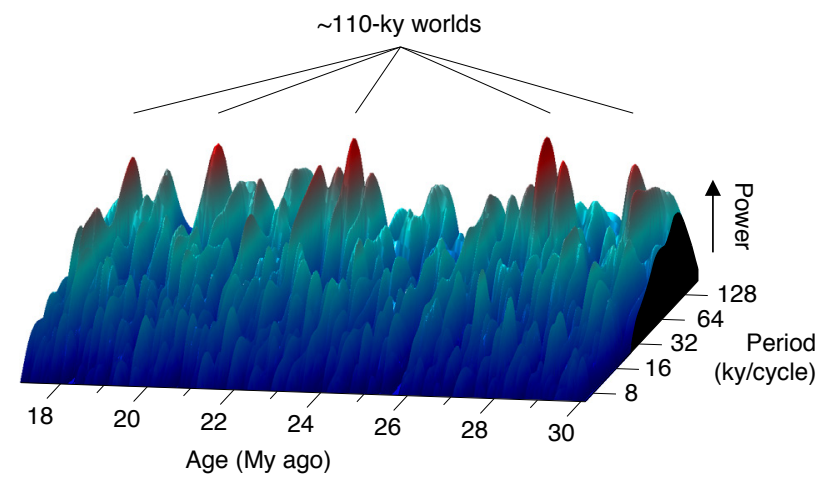




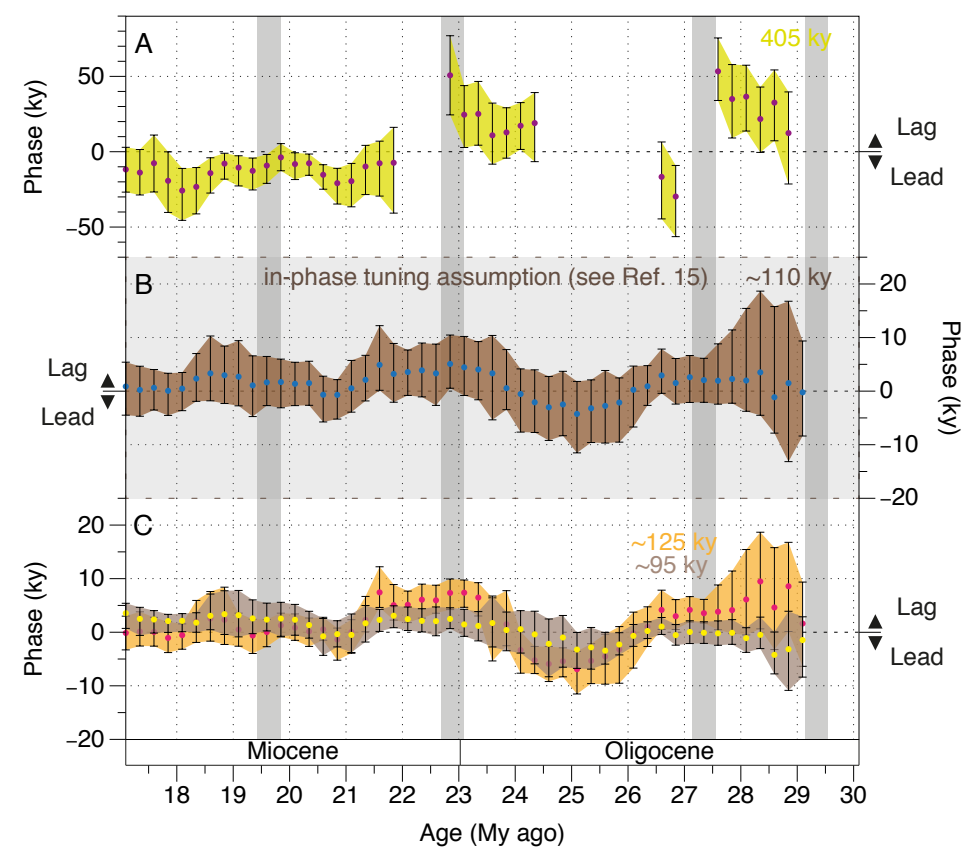




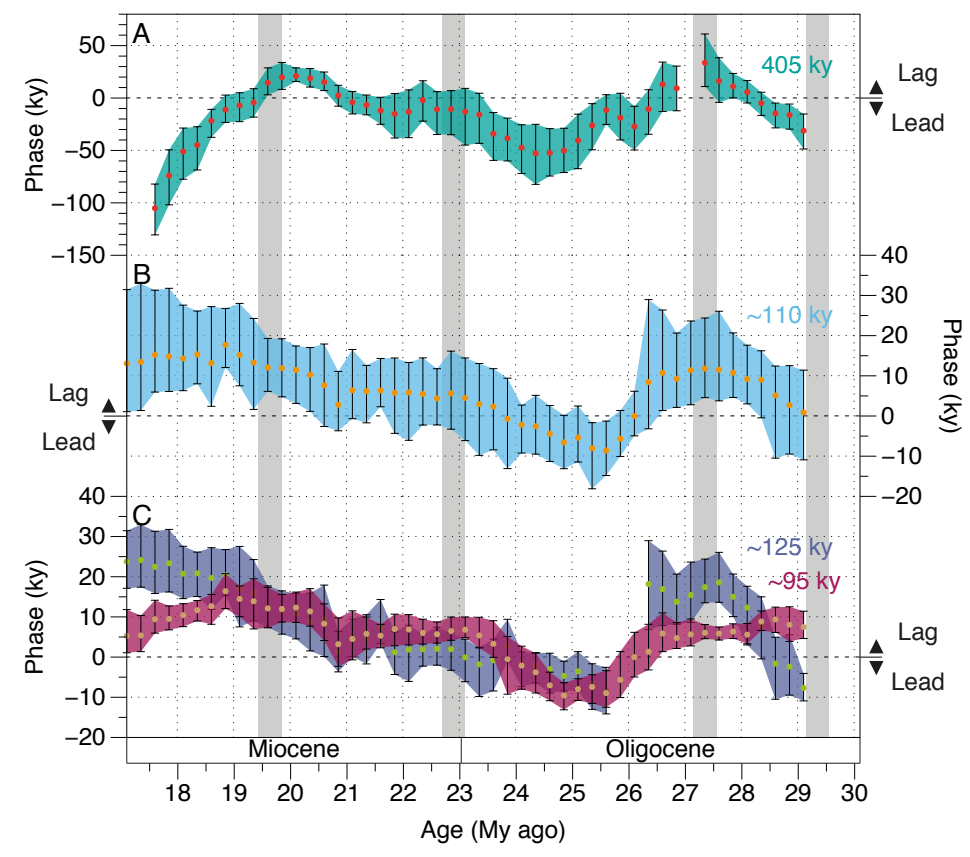



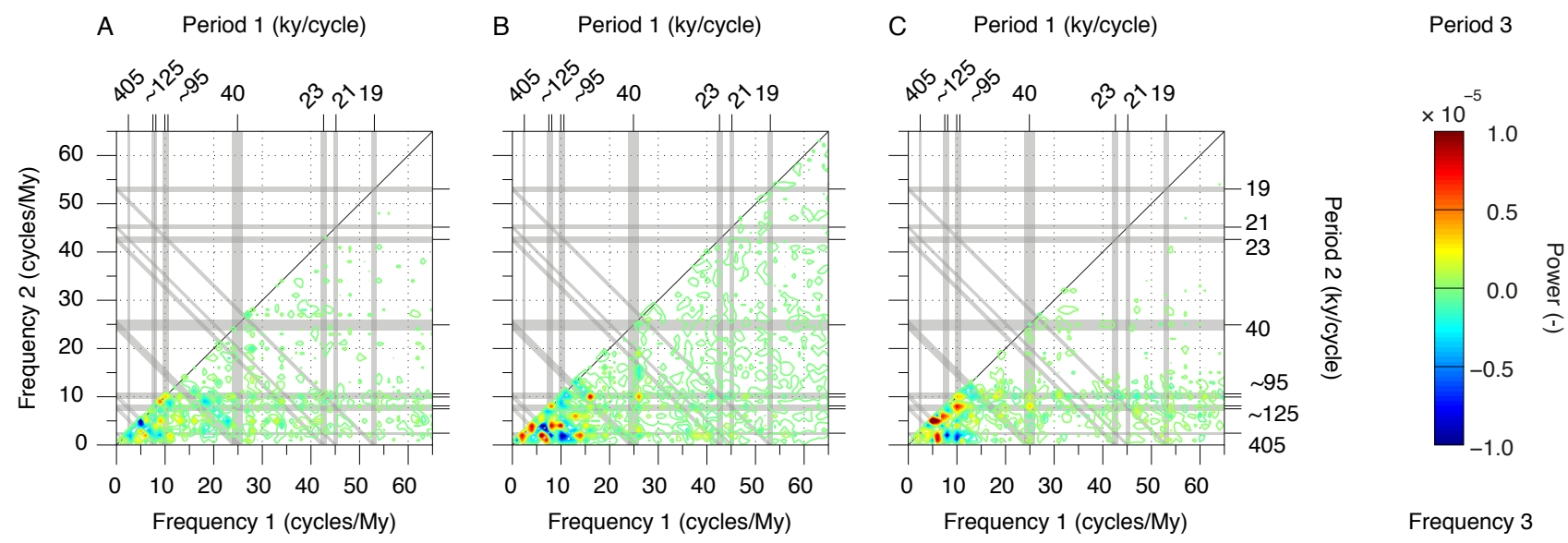

Frequency 3 

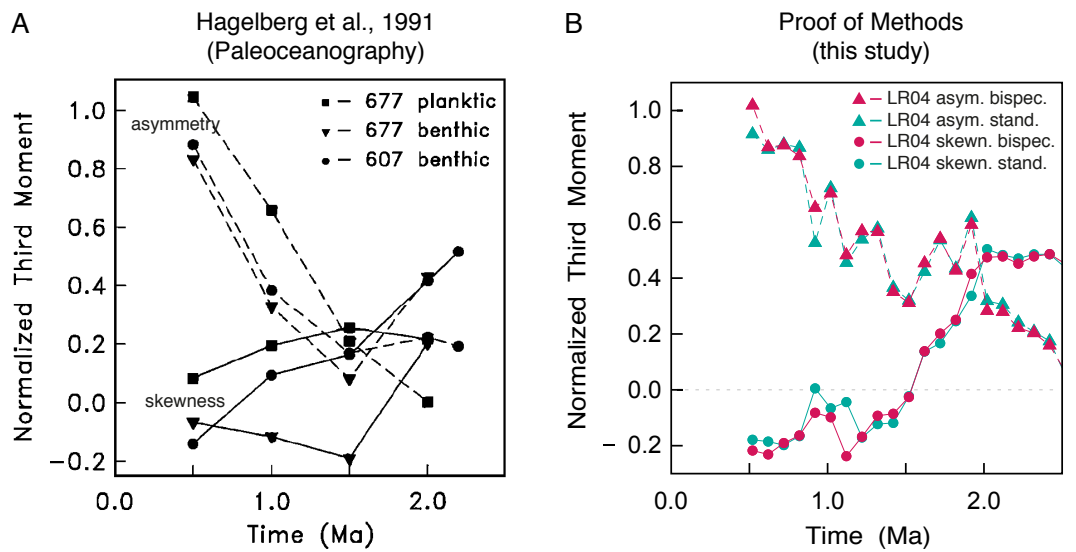


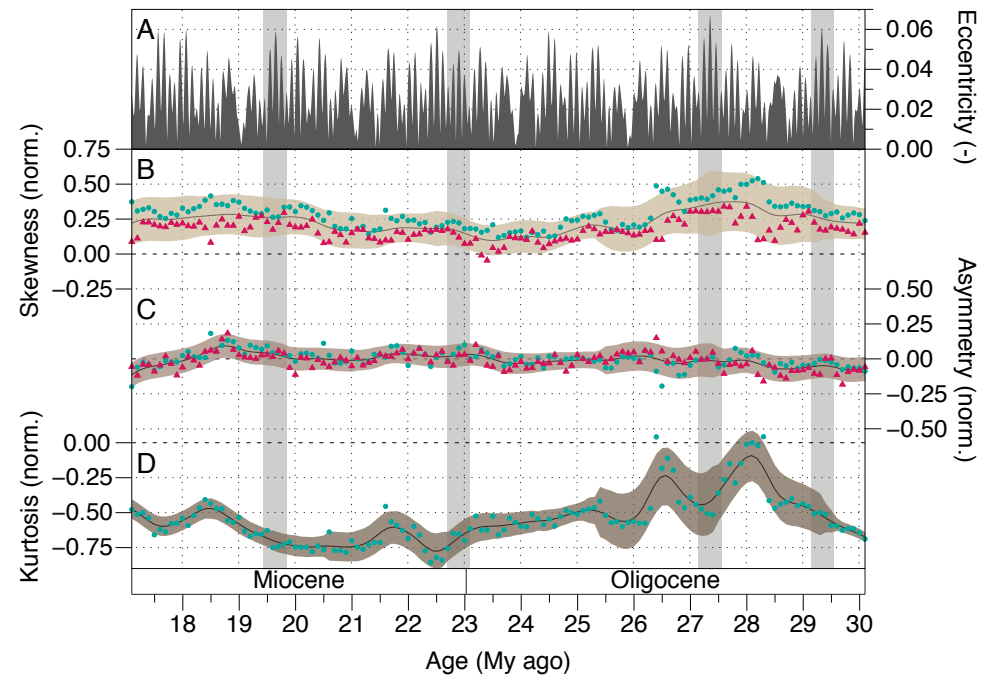




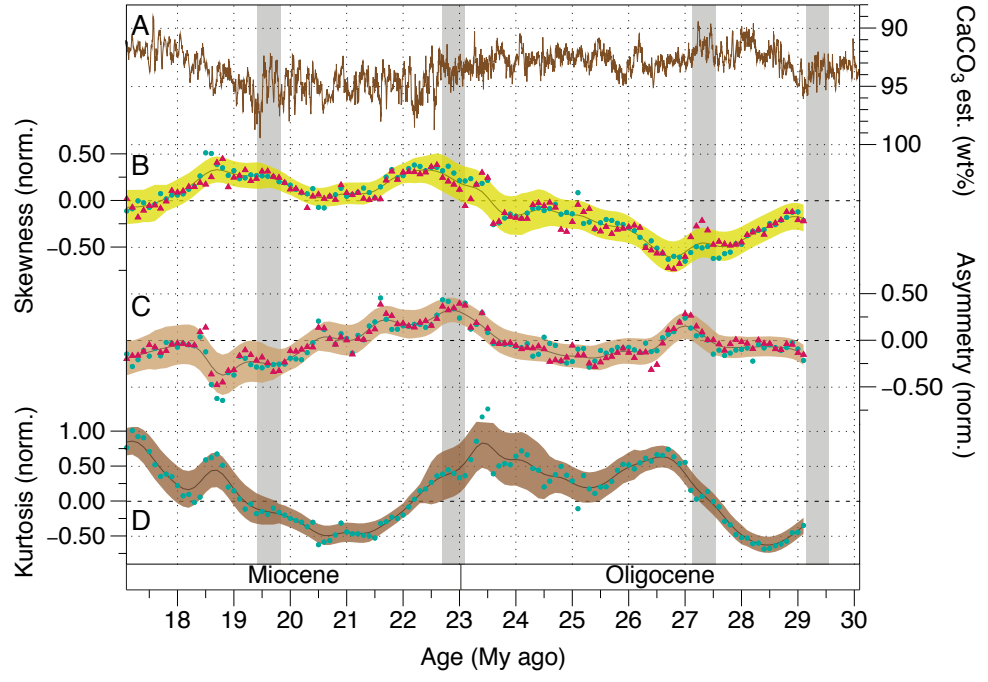



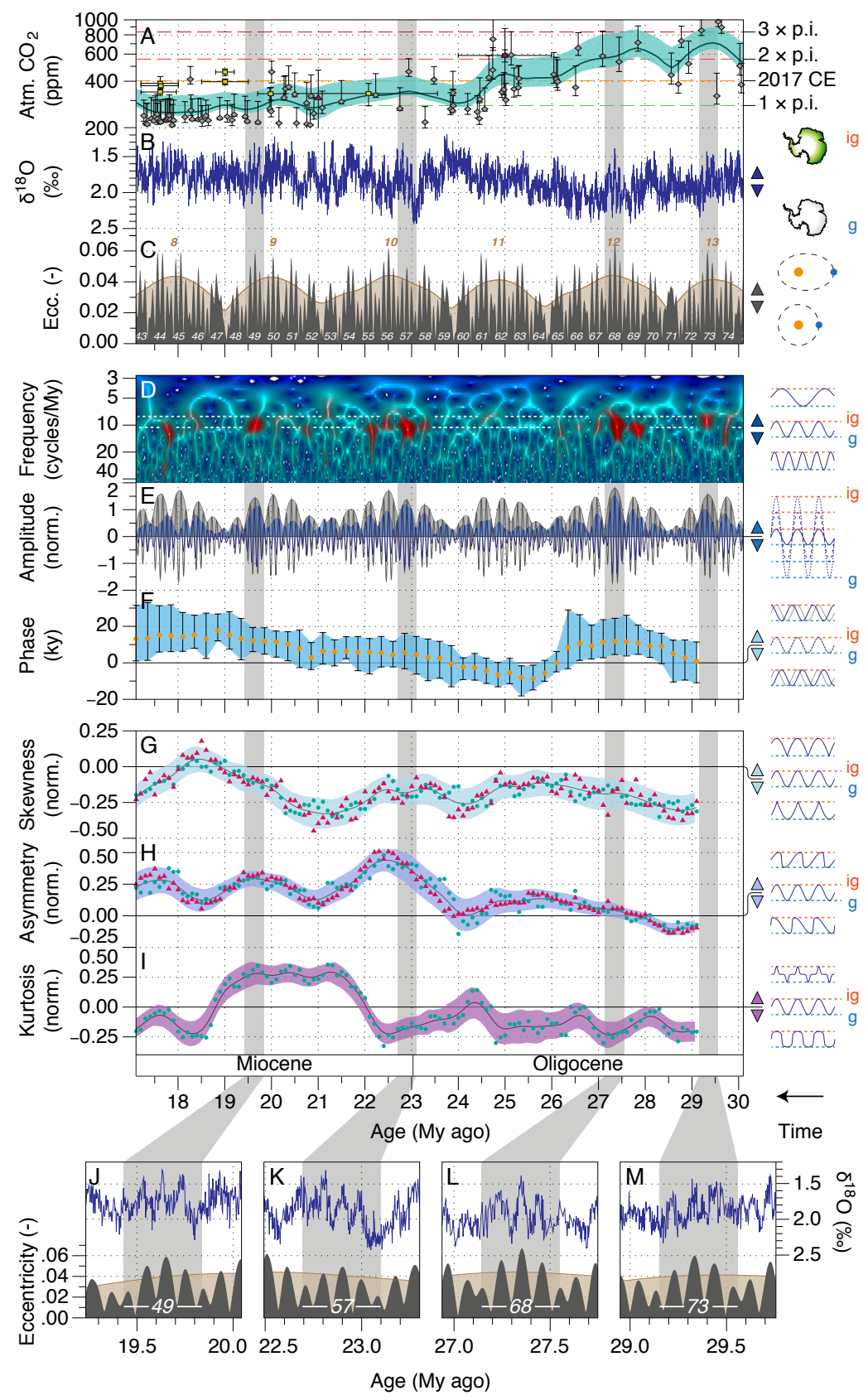